OPEN ACCESS

Edited by: Akikazu Shinya,

Nippon Dental University, Japan

Reviewed by:

Ajay Devidas Padsalgikar, DSM, United States Andre D. R. Silva,

Brazilian Air Force Academy, Brazil

*Correspondence:

Shang-Ming Lin

fc013@mail.oit.edu.tw

Wei-Jen Chang

cweijen1@tmu.edu.tw

${ }^{+}$These authors have contributed equally to this work

Specialty section: This article was submitted to Biomaterials, a section of the journal Frontiers in Materials

Received: 22 March 2021

Accepted: 03 May 2021

Published: 28 May 2021

Citation:

Salamanca E, Tsao T-C, Hseuh H-W, Wu Y-F, Choy C-S, Lin C-K, Pan Y-H, Teng N-C, Huang M-C, Lin S-M and

Chang W-J (2021) Fabrication of

Polylactic Acid/ß-Tricalcium Phosphate FDM 3D Printing Fiber to

Enhance Osteoblastic-Like

Cell Performance.

Front. Mater. 8:683706.

doi: 10.3389/fmats.2021.683706

\section{Fabrication of Polylactic Acid/ $\beta$-Tricalcium Phosphate FDM 3D Printing Fiber to Enhance Osteoblastic-Like Cell Performance}

\author{
Eisner Salamanca ${ }^{1 \dagger}$, Ting-Chia Tsao ${ }^{1,2 \dagger}$, Hao-Wen Hseuh ${ }^{1 \dagger}$, Yi-Fan $\mathrm{Wu}^{1}$, \\ Cheuk-Sing Choy ${ }^{3,4}$, Chin-Kai Lin ${ }^{5}$, Yu-Hwa Pan ${ }^{1,6,7,8}$, Nai-Chia Teng ${ }^{1,9}$, Mao-Chuan Huang ${ }^{2}$, \\ Shang-Ming Lin $^{2 *}$ and Wei-Jen Chang ${ }^{1,10 *}$ \\ ${ }^{1}$ School of Dentistry, College of Oral Medicine, Taipei Medical University, Taipei, Taiwan, ${ }^{2}$ Department of Materials and Textiles, \\ Oriental Institute of Technology, New Taipei City, Taiwan, ${ }^{3}$ Department of Community Medicine, En Chu Kong Hospital, New \\ Taipei City, Taiwan, ${ }^{4}$ Department of Nursing, Yuanpei University of Medical Technology, Hsin Chu, Taiwan, ${ }^{5}$ Department of \\ Dentistry, En Chu Kong Hospital, New Taipei City, Taiwan, ${ }^{6}$ Department of Dentistry, Chang Gung Memorial Hospital, Taipei, \\ Taiwan, ${ }^{7}$ Graduate Institute of Dental and Craniofacial Science, Chang Gung University, Taoyuan, Taiwan, ${ }^{8}$ School of Dentistry, \\ College of Medicine, China Medical University, Taichung, Taiwan, ${ }^{9}$ Dental Department, Taipei Medical University Hospital, Taipei, \\ Taiwan, ${ }^{10}$ Dental Department, Taipei Medical University, Shuang-Ho Hospital, Taipei, Taiwan
}

Guided-bone regeneration (GBR) is increasingly using three-dimensional (3D) printing by fused deposition modeling (FDM) to build the filaments used for treatment. Polylactic acid (PLA) and beta-tricalcium phosphate ( $\beta-T C P)$ are widely used as base materials in 3D printing, necessitating that they are studied together in the context of GBR treatment. This study sought to test and compare the properties and efficacy of different ratios of $\beta$-TCP and PLA used to make the 3D-printed filament material to find the most effective combination of materials for GBR treatment. Several ratios of PLA to $\beta$-TCP were tested, including PLA $\beta$-TCP ratios of 95\%/5\% (PLA-5), 90\%/10\% (PLA-10), 85\%/15\% (PLA-15), and 80\%/20\% (PLA-20), and quantitative real-time polymerase chain reaction (qPCR) in vitro testing was done to characterize the material. After adding $\beta$-TCP to PLA, mechanical testing indicated that tensile and elongation strengths decreased, hardness was retained, and cell proliferation was promoted. The effect of PLA and $\beta$-TCP on increasing alkaline phosphatase (ALP) activity was significantly greater in a ratio of $10 \%$ $\beta$-TCP/90\% PLA at 5 days $(p<0.05)$ than in any other ratios tested. This is supported by results from qPCR testing, which showed early osteoblast-like differentiation of DLX5, RUNX2, OPG, OC, and collagen type $1(\mathrm{COL}-1)$ expression levels similar to cells cultured on PLA-10. Our results demonstrated that 3D printing of filaments produced in a ratio of 90\% PLA to $10 \% \beta$-TCP was more effective for GBR than that of filaments produced only using PLA.

Keywords: PLA/ $\beta-T C P, 3 D$ printing, bone regeneration, MG-63, fused deposition modeling 


\section{INTRODUCTION}

Bone graft materials used in GBR treatment have the biologic property of osteoconduction or osteoinduction to promote or accelerate bone healing (LeGeros et al., 2003). Synthetic grafts are utilized mainly as osteoconductive scaffolding as a substitute for autografts or other grafting materials (Causa et al., 2006). Their advantages include the controllable preparation method, controllable degradation, mechanical properties, and strong plasticity. Synthetic grafts do not have antigenicity properties and do not carry a potential risk of disease transmission (Ohgushi et al., 1990). The potential for development and clinical application makes synthetic grafts a very promising material for GBR techniques (Chuenjitkuntaworn et al., 2010). Some of these grafts can be hydroxyapatite (HAp), whitlockite, and alphaor beta-tricalcium phosphate (TCP), with each one of them having specific bioactive features (Jeong et al., 2019). The main components of HAp and TCP materials are calcium and phosphorus, which are also found in the inorganic components of the human bone. Both, HAp and TCP, are composite ceramics that are widely used in dentistry and orthopedics bone defect research (Takagi et al., 2018).

TCP is a bone replacement biomaterial with its molecular formula $\mathrm{Ca}_{3}\left(\mathrm{PO}_{4}\right)_{2}$, which can be transformed into two types of $\alpha$-TCP or $\beta$-TCP phases by using specific temperatures (Moreno et al., 2020). The TCP calcium-to-phosphorus ratio is 1.5 , which is close to that of normal bone tissue. There are two forms of TCP: $\alpha$-TCP and $\beta$-TCP, mainly prepared by chemical synthesis. Because $\alpha$-TCP has a higher sintering temperature, its crystallinity and compressive strength are greater than those of $\beta$-TCP, but its biologic activity is not effective. In addition to its good osteoconductivity and biocompatibility, $\beta$-TCP is degradable most prominently in the body and, under normal circumstances, is 10-15 times more soluble than HAp (LeGeros, 1988). Although the biocompatibility and biologic activity of $\beta$-TCP-guiding or -stimulating bone regeneration are satisfactory, it does not inhibit bone resorption.

When used as a graft material in the bone regeneration process, biodegradable polymers can be shaped into bone defects and accelerate the new bone formation. Biodegradable polymers have special hydrophilic surface properties, which are conducive to cell attachment. Polylactic acid is a biodegradable polymer with good biocompatibility, is naturally metabolized and absorbed in the human body, and has good mechanical properties, making it a useful material for surgical sutures, drug release, bone graft, and artificial skin dressing surfaces. The mechanical properties of this material, however, must be strengthened to make it a more suitable material for repairing bone defects.

$3 \mathrm{D}$ printing is getting popular to restore alveolar bony deficiency. Fused deposition modeling (FDM) and stereolithography (SLA) are the two most popular types of 3D printers on the market. FDM is also called fused filament fabrication (FFF) and is a $3 \mathrm{D}$ printing process that uses a continuous filament of a thermoplastic polymer material (Hamzah et al., 2018). The method uses heat to melt and extrude the raw materials. As the material is extruded, the nozzle moves back and forth to form the layers, which bond to each other without adhesive or solvent (Hallermann et al., 2006; Murphy and Atala, 2014). Previous studies have used 3D printing to manufacture membranes for tissue engineering by mixing $\beta$-TCP with polymers. An in vitro study using PLA/ $\beta$-TCP composite scaffolds demonstrated significantly enhanced proliferation of human adipose stem cells and total alkaline phosphatase (ALP) activity when cultured with PLA/ $\beta$-TCP (Haimi et al., 2009). The authors suggested that this supported the potential use of PLA/ $\beta$-TCP composites as effective scaffolds for tissue engineering and as bone replacement materials. Furthermore, studies are necessary after in vitro (Cipitria et al., 2011; Dan et al., 2014) and in vivo studies demonstrating that the biocompatibility and bone regeneration properties of 3D-printed polycaprolactone (PCL)/ $\beta$-TCP $80 / 20 \%$ ratio membranes were more effective than those of $3 \mathrm{D}$-printed PCL alone and substantially better than those of conventional collagen membranes (Shim et al., 2017), opening the possibility of using $3 \mathrm{D}$-printed PLA/ $\beta$-TCP for bone regeneration in the reconstruction of osseous defect treatment (Aydogdu et al., 2019; Donate et al., 2020; Joshi et al., 2020).

New imaging technology exists to scan the shape of a bone defect before a bone defect regeneration procedure is done in a patient. To develop the personalized treatment plans via $3 \mathrm{D}$ printed technologies, use PLA as raw material for a 3D-printed graft customized to the bone defect specific shape and implant the synthetic graft in the bone defect has been developed (Rasperini et al., 2015). The question is whether the mechanical properties of PLA can be enhanced by combining it with bioactive ceramics, such as TCP or HAp, and whether this composite material expands both the mechanical and biologic effectiveness of PLA as a synthetic graft (Rajendran and Venugopalan, 2015; Abe et al., 2020). Therefore, in the present study, we tested and compared the properties and efficacy of different ratios of $\beta$-TCP and PLA used to make the $3 \mathrm{D}$-printed filament material to find the most effective combination of materials for infrabony defect treatment.

\section{MATERIALS AND METHODS}

\section{Material Preparation}

Different ratios of PLA (molecular weight: $60.000 \mathrm{Mn}, 38534-1 \mathrm{G}$ Sigma-Aldrich) to $\beta$-TCP (molecular weight: $310.18 \mathrm{Mn}, 21218$ 1 KG Sigma-Aldrich) were mixed: $95 \%$ PLA to $5 \% \beta$-TCP; $90 \% /$ $10 \% ; 85 \% / 15 \%$; and $80 \% / 20 \%$. The mixtures were each classified with a PT73 code. The mixture process started by pouring $\beta$-TCP and PLA materials into a single screw extruder (single screw mixer; Filabot EX2 and spooler; Filabot, Barre, VT, United States) equipped with a circular aperture of 3-mm diameter for mixing and extrusion. The resulting PLA $/ \beta$-TCP composite material was extruded as a $1.75-\mathrm{mm}$ diameter filamentous material.

\section{Material Characterization}

\section{Scanning Electron Microscopy and Energy Dispersive Spectrometry}

We used scanning electron microscopy (SEM) and energy dispersive spectrometry (EDS) to analyze the sample surface 


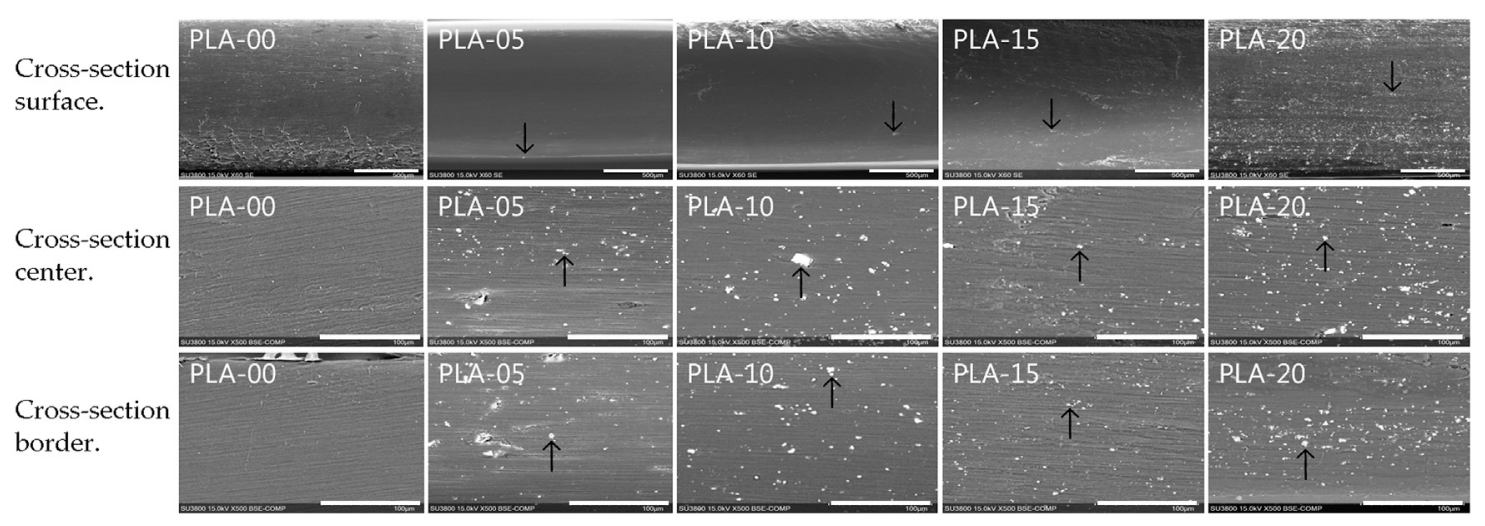

FIGURE 1 | SEM micrographs of the different PLA $\beta$-TCP filaments. Three sections in each filament show the amount of $\beta$-TCP microparticle agglomeration with some macroparticles through the filaments. Cross-section surface images' scale bar is $500 \mu \mathrm{m}$. Black arrows indicate $\beta$-TCP particles. Cross-section center and border images' scale bar is $100 \mu \mathrm{m}$.

structure and element distribution. A layer of gold film of 50 to $200 \AA$ thickness was sputtered on the surfaces of the PLA/ $\beta$-TCP filaments. Selected longitudinal surface areas were chosen for microphotography at the surface, cross center, and cross border of the filaments obtained $(\times 1.0 \mathrm{~K}, 15 \mathrm{KV})$. Microphotography was taken with a scanning electron microscope (Hitachi SU 3500, Kyoto, Japan) and sampling analysis by energy dispersive spectroscopy (Figure 1).

\section{Inductively Coupled Plasma}

The ion concentration in the PLA/ $\beta$-TCP filaments was analyzed using inductively coupled plasma-optical emission spectrometry ([ICP-OES] iCAP 7000; Thermo Fisher Scientific, Waltham, MA, United States) and determined by comparison with a standard curve that was generated using solutions of known concentration.

\section{PLA/ $\beta$-TCP Filaments' Mechanical Testing}

Mechanical testing was performed on seven samples following ISO-527-1993, including D638 for tensile strength/modulus and D412 for hardness. Per ASTM D638-14, a specimen thickness of $3.33 \times 10^{-2} \mathrm{~s}^{-1}(5 \mathrm{~mm} / \mathrm{min})$ was given for type IV $(25 \mathrm{~mm})$ specimens.

The averages were recorded as the value of the corresponding mechanical test. Standards from the American Society for Testing and Materials were applied. The tests were carried out on a Shimadzu AGX-V mechanical testing machine (Kyoto, Japan).

\section{Fourier Transform Infrared Spectroscopy}

Fourier transform infrared spectroscopy used infrared light to detect the infrared absorption, and emission spectra of PLA/ $\beta$-TCP filaments were characterized using a Nicolet $^{\mathrm{TM}}$ iS5 FTIR Spectrometer (iD5 Diamond attenuated total reflection) with the scan number of 16 and resolution of $4 \mathrm{~cm}^{-1}$. Samples were analyzed in the $1850-650 \mathrm{~cm}^{-1}$ wavenumber range and transmittance mode at $25^{\circ} \mathrm{C}$ and $65 \% \pm 5 \%$ humidity. The peak position, intensity, and shape of the PLA/ $\beta-T C P$ filaments were analyzed to detect the functional groups of organic compounds in the samples and test the changes in the PLA-related peaks before and after PLA and $\beta$-TCP were mixed.

\section{Cell Viability}

Cell viability was evaluated with osteoblast-like cells (MG-63 cell line, ATCC CRL-1427) used for experimentation. The cells were cultured in Dulbecco's modified Eagle's medium containing $4 \mathrm{mM}$ L-glutamine, $10 \%$ fetal bovine serum (FCS), and $1 \%$ penicillin (HyClone Laboratories, Logan, UT, United States). The cells were cultured in Petri dishes (Nunclon; Nunc A/S, Roskilde, Denmark) with a base area of $78.5 \mathrm{~cm}^{2}$ containing $10 \mathrm{ml}$ of cell culture medium at a density of $1 \times 10^{5}$ cells $/ \mathrm{ml}$. Cell growth was expressed in cells $/ \mathrm{ml}$. The cells were cultured at $1 \times 10^{4}$ cells/ $\mathrm{ml}$ in a cell incubator containing $5 \% \mathrm{CO}_{2}$ at $37^{\circ} \mathrm{C}$ and $100 \%$ humidity. During subculture, the cells were washed three times with buffer solution and treated with $0.25 \%$ trypsin/ ethylenediaminetetraacetic acid (EDTA) at $37^{\circ} \mathrm{C}$ for $10 \mathrm{~min}$. The suspended cells were centrifuged at 1,000 revolutions per minute for $5 \mathrm{~min}$ at $25^{\circ} \mathrm{C}$. After removing the supernatant, the cells were resuspended in a centrifuge tube for counting.

\section{Cell Proliferation Assay}

The cell proliferation assay used the bromide (MTT) method. The principle was to use the mitochondrial dehydrogenase in living cells to make the yellow soluble tetrazolium-3, 4 (4,5dimethylthiazol-2-yl)-2,5-diphenyltetrazolium bromide. After the MTT salt turned into a dark purple insoluble formazan crystal, it was dissolved in sodium dodecyl sulfate solution, and the optical density value was measured to determine cell proliferation. The PLA/ $\beta$-TCP 3D discs were placed in 24 -well culture dishes. Later, the MG-63 cells were dropped in the wells at a density of $1 \times 10^{4} \mathrm{cell} / \mathrm{cm}^{2}$. Wells with no discs in them were used as the control groups.

After $0 \mathrm{~h}$, and then at 1,3 , and 5 days, the culture medium was aspirated and $500 \mu$ ldimethyl sulfoxide (DMSO) was added, followed by the addition of $50 \mu \mathrm{l}$ MTT. Cell proliferation was observed with the absorbance value of the enzyme-linked immunosorbent assay reader at $595 \mathrm{~nm}$. Each condition was 
given in four replicates, and the average results were compared between all groups. Cell viability was expressed as the percentage of MTT reduction, assigning the $100 \%$ value to the absorbance of the control cells.

\section{Alkaline Phosphatase Activity}

The standard curve of protein concentration was established. The concentration of FCS albumin was $1.38 \mathrm{mg} / \mathrm{ml}$, and different concentrations were diluted as needed. For each well, $100 \mu \mathrm{l}$ was removed, and $5 \mathrm{ml}$ Bio-Rad protein analysis reagent was added. After reacting for $15 \mathrm{~min}$, the absorbance spectrodensity value changes were measured by a spectrometer at a wavelength of $595 \mathrm{~nm}$, and the changes in the spectrodensity of different concentrations of protein were evaluated. A standard curve of relative absorbance was used. To determine the protein concentration, the concentration of protein $(\mathrm{mg} / \mathrm{ml})$ may be estimated from the change in the absorbance value of the sample.

The ALP activity and protein concentration were determined with MG-63 by homogenization. A total of $200 \mu \mathrm{l}$ was removed from the homogenization solution, and $2 \mathrm{ml}$ substrate solution containing 4-nitrophenyl phosphate (Merck, Schuchardt, Hohenbrunn bei Munchen, Germany) was added. When the substrate was hydrolyzed by ALP, a yellow product (nitrophenol) formed later. The change in absorbance was measured at a wavelength of $405 \mathrm{~nm}$, and the activity of ALP (unit/L) was determined.

A total of $100 \mu \mathrm{l}$ of the homogenized solution was removed and added to the Bio-Rad protein analysis reagent. The absorbance value was measured at a wavelength of $595 \mathrm{~nm}$ by the spectrometer, and after conversion with the protein standard curve, the protein concentration $(\mathrm{mg} / \mathrm{ml})$ was measured. After converting the activity of ALP to the protein concentration, the activity of ALP contained in each milligram of protein was obtained in units/mg protein.

\section{Reverse Transcription and Quantitative Real-Time Polymerase Chain Reaction (qPCR)}

The quantification of all gene transcripts was performed at days 1 , 3 , and 5. Following the manufacturer's instructions, Novel Total RNA Mini Kit (NovelGene, Molecular Biotech, Taiwan) was briefly used for RNA extraction and purification (Bimboim and Doly, 1979; Vogelstein and Gillespie, 1979; Choy et al., 2019), to be later quantified with an ND-1000 spectrophotometer (Nanodrop Technology, Wilmington, DE, United States). Each sample was stored at $-20^{\circ} \mathrm{C}$ for real-time polymerase chain reaction (qPCR) analysis.

The expression levels of distal-less homeobox 5 (DLX5), Osterix (SP7), collagen type I (COL-1) runt-related transcription factor 2 (RUNX2), osteoprotegerin (OPG), osteocalcin (OC), bone sialoprotein (BSP), and receptor activator of nuclear factor kappa-B ligand (RANKL) were quantified. Gene expression levels were normalized to the expression level of the housekeeping gene glyceraldehyde phosphate dehydrogenase (GAPDH). Forward and reverse primer sequences were designed using Primer-BLAST from the U.S. National Library of Medicine (Sollazzo et al., 2010; Salamanca et al., 2020). A time-course analysis of the cell's genes was done while comparing them to control genes. The genes of the control cells were settled as the calibrator sample, representing the amount of transcript expressed at day 0 of cells cultured only in Dulbecco's modified Eagle's medium (DMEM) (Livak and Schmittgen, 2001). Real-time PCR was performed using $2 \mu \mathrm{l}$ of cDNA in $20 \mu \mathrm{l}$ of reaction volume using a LightCycler ${ }^{\circledR} 96$ Instrument, an application software (Roche Molecular Systems, Inc., California, United States), and the Fast SYBR ${ }^{\mathrm{TM}}$ Green Master Mix (Thermo Fisher Scientific, Vilnius, Lithuania). The temperature profile of the reaction was $95^{\circ} \mathrm{C}$ for $10 \mathrm{~min}$, followed by 40 cycles of denaturation at $95^{\circ} \mathrm{C}$ for $15 \mathrm{~s}$, annealing at $60^{\circ} \mathrm{C}$ for $60 \mathrm{~s}$, and extension at $72^{\circ} \mathrm{C}$ for $30 \mathrm{~s}$. Quantification was performed using the delta-delta calculation method.

\section{Statistical Analysis}

The results are expressed as the mean \pm standard deviation, except for the qPCR results, which are expressed as the mean \pm standard error. Statistical evaluation of the data was performed with Student's t-test for simple comparison between two values, when appropriate. The comparisons were performed using Excel version 2011 (Microsoft, Redmond, WA, United States). The data were analyzed using analysis of variance, with $p<0.05$ considered statistically significant.

\section{RESULTS}

\section{Scanning Electron Microscopy and Energy Dispersive Spectrometry Testing}

Different ratios of PLA to $\beta$-TCP were mixed: $95 \%$ PLA to $5 \%$ $\beta$-TCP (PLA-5); 90\%/10\% (PLA-10); 85\%/15\% (PLA-15); and $80 \% / 20 \%$ (PLA-20), and compared to PLA (PLA-00) alone as control. Morphologic and element analysis of PLA $/ \beta-T C P$ filaments was performed with SEM and EDS. Figure 1 shows the growth of filaments in each ratio in longitudinal cross-section in various tissue regions. All filaments formed a heterogeneous PLA/ $\beta$-TCP matrix.

Figure 1 shows that $\beta$-TCP in a ratio of $5 \%$ (PLA-05) resulted in a morphology that mainly consisted of a uniform dispersion of $\beta$-TCP macrofillers and microfillers less than $7 \mu \mathrm{m}$ in size and almost circular in shape in a homogeneous distribution matrix comprising PLA/ $\beta$-TCP. At higher $\beta$-TCP ratios (90\% PLA [PLA10]; 85\% PLA [PLA-15]; and 80\% PLA [PLA-20]), particles remained uniformly dispersed through the border and center of the filaments with no separation between the materials, indicating a strong interaction between them.

\section{$\beta$-TCP Release Mass}

The $\beta$-TCP release mass of different concentrations on the PLA/ $\beta$-TCP filaments was quantified by ICP-OES. The results are presented in Table 1 and Figure 2. The results indicated that wt $\%$ was almost exactly in the desired PLA/ $\beta$-TCP ratios.

\section{Mechanical Properties}

The results of mechanical property testing showed that PLA had high strength, low flexibility, and medium lifespan durability. The 
TABLE 1 | PLA/ $\beta$-TCP filament weight ratio percentages achieved.

\begin{tabular}{|c|c|c|c|c|}
\hline Symbol & $\beta$-TCP/PLA (wt\%) & $\beta$-TCP powder (g) & PLA (g) & Actual ratio (wt\%) \\
\hline PLA-05 & 5 & 15 & 285 & 5.5 \\
\hline PLA-10 & 10 & 30 & 270 & 10.9 \\
\hline
\end{tabular}

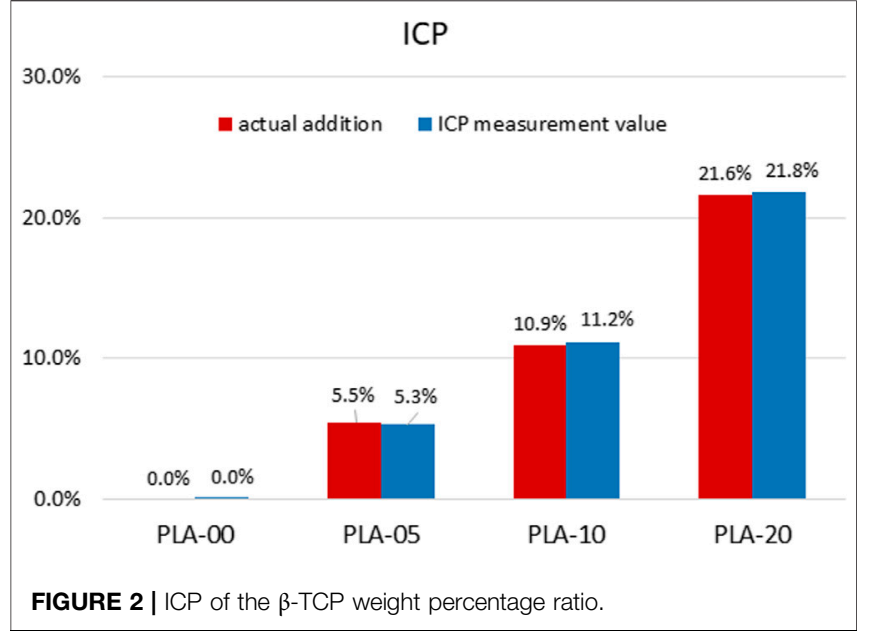

flexural strength was higher than the tensile strength, usually in brittle materials with low elongation percentages. The addition of $\beta$-TCP to PLA lowered the tensile (Figure 3A) and elongation properties (Figure 3B) and slightly the hardness (Figure 3C) (statistically significant difference appears in Figure 3). The results demonstrated that, for all PLA $/ \beta$-TCP ratios, PLA-10 underwent the least statistically significant difference modification when compared to PLA-00, followed by PLA-5 and PLA-20. These findings are shown in Figure 3. The viable cell ratio increased with time for all PLA $/ \beta$-TCP ratios, and concentrations were like those in the positive control (Figure 4). The viable cell ratios for all concentrations of PLA were higher at day 5 compared to days 1 and 3. Compared to control at day 1 , the PLA/ $\beta$-TCP at day 5 was $328 \%$ in PLA-20, $330 \%$ in PLA-00, 342\% in PLA-05, and 341\% in PLA-10. Despite these increases shown by day 5 , all PLA/ $\beta$-TCP ratios were slightly lower than the control, with $92.10 \%$ in PLA-20, 96.52\% in PLA-00, $100.38 \%$ in PLA-05, and $103.97 \%$ in PLA10 . The best PLA/ $\beta$-TCP ratio after 5 days was $10 \%$ PLA (PLA$10)$, which had greater cell viability compared to the other filaments; however, the proliferation of cell growth regardless of the ratio of PLA to $\beta$-TCP means that all PLA/ $\beta$-TCP ratios can be considered nontoxic. The same tendency as in the MTT assay was found in the proliferative changes of MG-63 cells, which indicated that most of the cells proliferated in the media with PLA/ $\beta$-TCP filaments. Furthermore, on light microscopy, denser colony formation was observed in all wells after 5 days (Figure 5).

\section{Fourier Transform Infrared Results}

Fourier transform infrared (FTIR) results showed that all PLA/ $\beta$-TCP filaments mimicked the PLA pattern. One PLA region of interest commonly is 1,780 and $1,680 \mathrm{~cm}^{-1}$ for the $\mathrm{C}-\mathrm{O}$ stretch. Our study depicted a clear stretch of the carbonyl group $(\mathrm{C}=\mathrm{O})$ of the ester bond at approximately $1,748 \mathrm{~cm}^{-1}$ along with a symmetrical-C-O-C stretch at $1,180 \mathrm{~cm}^{-1}$ and an asymmetrical- $\mathrm{CH}_{3}$ stretch at $1080 \mathrm{~cm}^{-1}$. This is the same result as previously reported (Awale et al., 2018). When $\beta$-TCP was added to PLA, similar patterns of the same width were clearly visible in all PLA ratios, but the peaks were lower. The results demonstrated that the higher the proportion of $\beta$-TCP, the lower the percentage of transmittance in the same waves (Figure 6).

\section{Alkaline Phosphatase Activity}

Alkaline phosphatase (ALPase) activity was slightly increased in the osteoblast-like cells cultured in the PLA/ $\beta$-TCP filaments compared to the control group at days 1, 3, and 5. Regardless of the ratio of $\beta$-TCP to PLA, all groups had ALPase activity in the cells exposed to the PLA/ $\beta$-TCP filaments. Figure 7 shows that the effect that PLA-10 had on increasing ALPase activity at day 5 was significantly greater than that of the other ratios $(p<0.05)$.
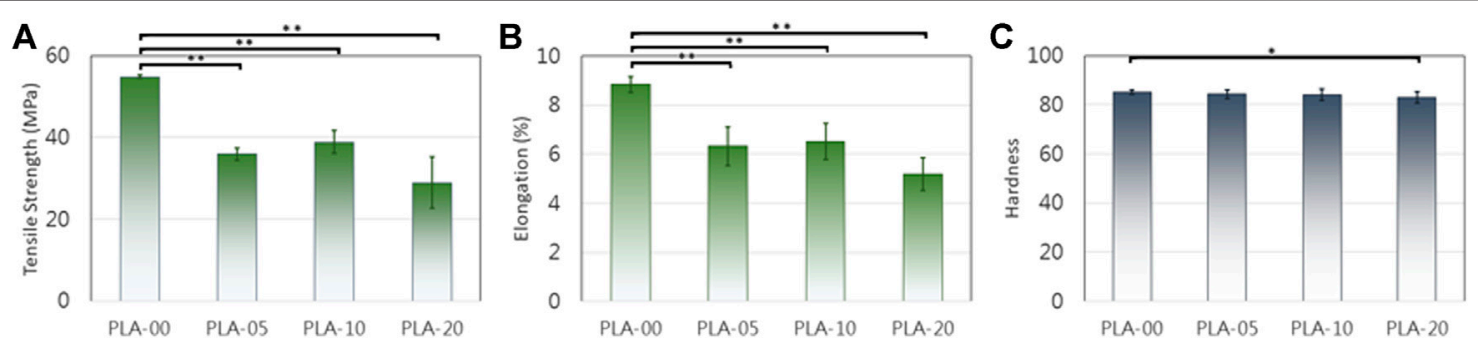

FIGURE 3 | PLA mechanical changes after $\beta$-TCP addition. (A) and (B) D638 tensile strength/modulus. (C) D412 hardness ( $\left.{ }^{*} p<0.05,{ }^{\star *} p<0.01\right)$. 


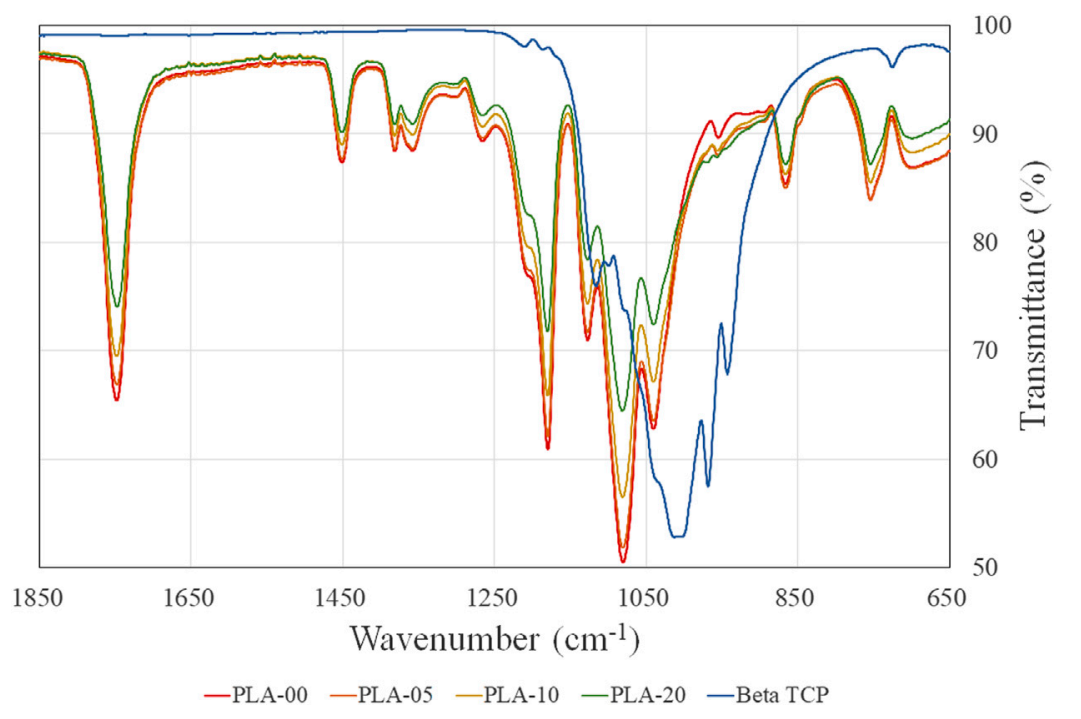

FIGURE 4 | Cell proliferation assay. All PLA/ $\beta$-TCP ratios were nontoxic, leading to cell proliferation during 5 days $\left({ }^{*} p<0.05\right)$.

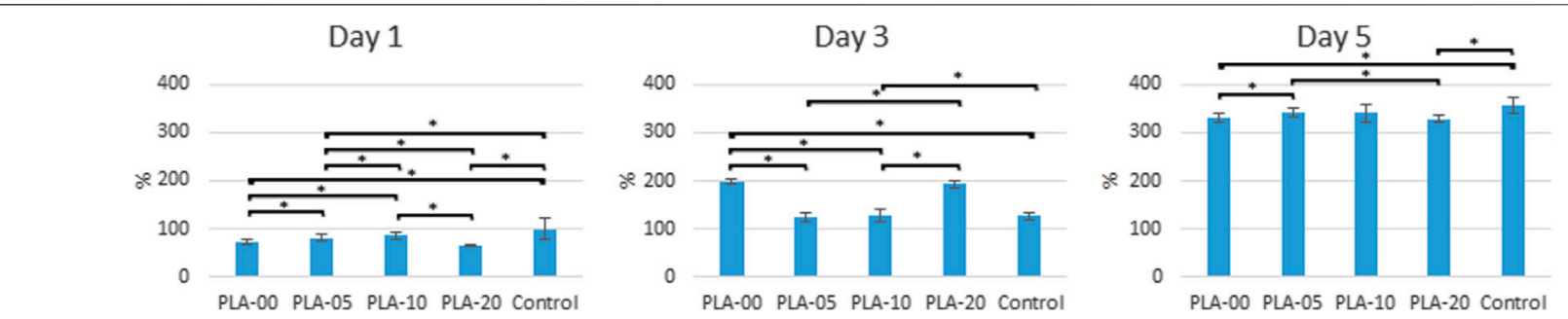

FIGURE 5 | Proliferative changes of osteoblast-like cells cultured on PLA/ $\beta$-TCP filaments. Images were captured at $10 \times$ magnification. All bars = $50 \mu$ m.

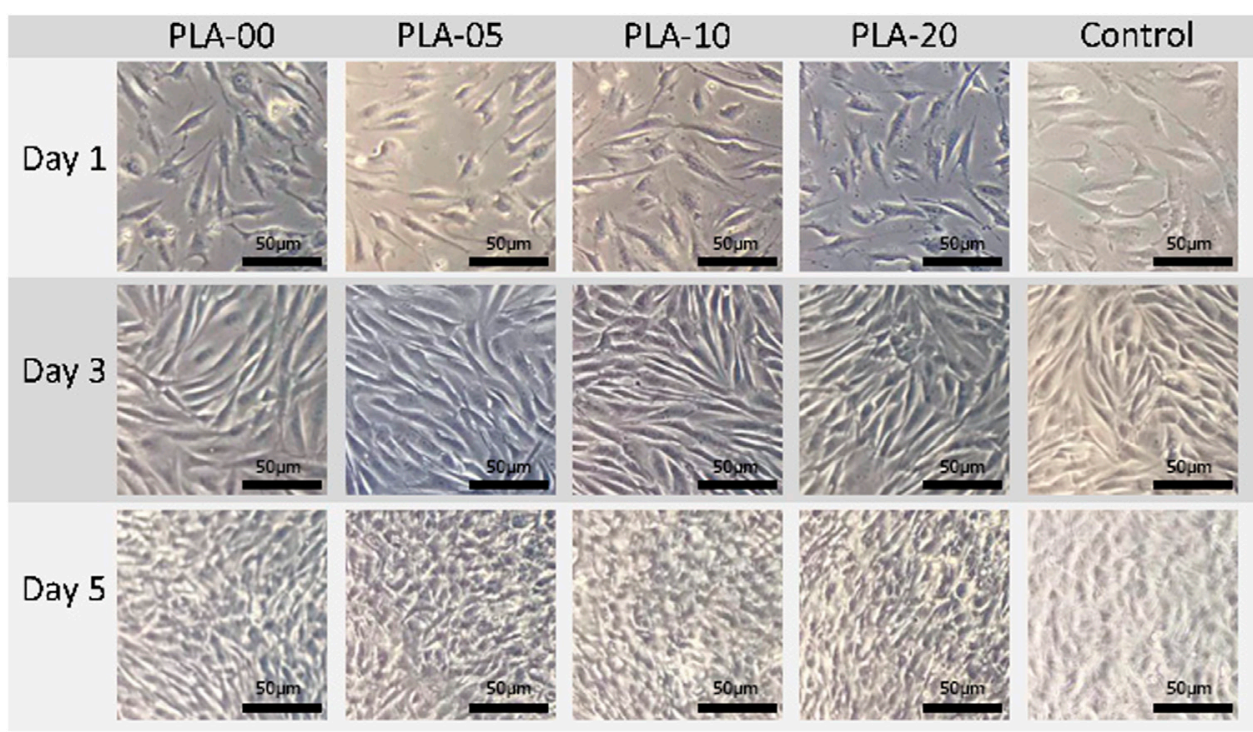

FIGURE 6 | FTIR spectra of PLA alone and with different $\beta$-TCP contents. 


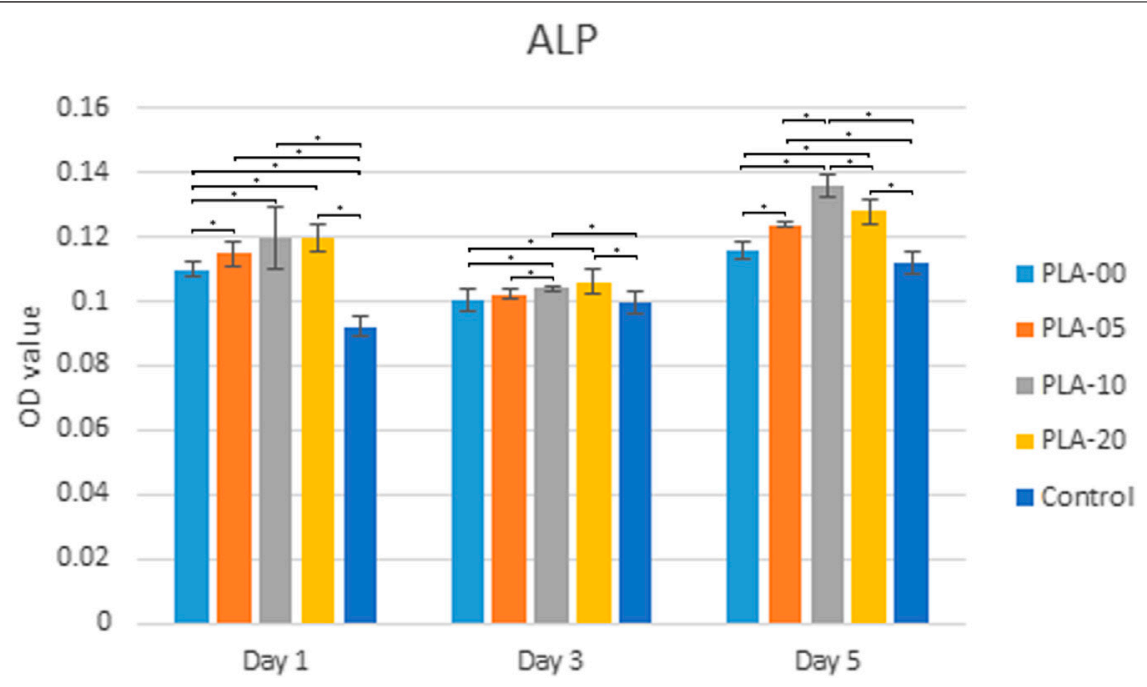

FIGURE 7 | ALPase activity. PLA-10 and PLA-20 demonstrated significant ALPase performance $\left({ }^{*} p<0.05\right)$ at days 1,3 , and 5.

\section{Real-Time PCR}

Overall, the cells cultured on the medium with PLA/ $\beta$-TCP filaments had higher mRNA expression levels of DLX5, SP7, COL-1, OPG, OC, BSP, and RUNX2 than those cultured in DMEM, except for the RANKL that did not have any mRNA expression levels in any of the samples during the different time sets. The levels of gene expression were higher in cells cultured in the PLA-10 medium on the first day and decreased sharply at day 3 and later day 5. Cells cultured in the PLA-20 media had similar gene expression levels of 2 at day 1 and slightly reduced at days 3 and 5. Cells cultured in PLA-0 and PLA-20 media had a mixed expression of the genes at the three time sets. The expressions in COL-1 were higher for cells cultured on PLA-20 only at day 5 (statistically significant difference appears in Figure 8).

\section{DISCUSSION}

Recently, bone tissue engineering has aimed to use osteoconductive scaffolds and the delivery of osteogenic cells and biologic factors (Khojasteh et al., 2016); however, faster and high-resolution fused deposition modeling printers along with new advanced biomaterials and carrier agents are necessary for 3D printing (Ahmad et al., 2019). The PLA/ $\beta$-TCP filament could be this advanced new biomaterial 3D printed in low-cost machines that can be used in masses, therefore, in every dental office. Based on our cytotoxicity assessments of various PLA $/ \beta$-TCP mixtures at different concentrations and extracted at different periods of time, we found the most effective ratio of PLA to $\beta$-TCP for the FDM filament with relatively low cost.

Polylactic acid is a resorbable, low-cost, stiff material with good strength and shelf life. It is a biodegradable, environmentally friendly polymer produced from cornstarch and is not harmful to the environment when compared to petroleum-based plastics (Ayrilmis et al., 2019). Polylactic acid is often used in 3D allograft printing but can result in filaments that can become brittle and break. Beta-tricalcium phosphate is from the calcium phosphate family and has excellent osteoconductivity and similarity to the bone mineral ceramic phase. It has been used extensively in orthopedics, oral and plastic surgeries, and bone tissue engineering; however, the effectiveness of porous $\beta$-TCP is limited because of its brittleness and poor mechanical properties (Khojasteh et al., 2016).

In combination with PLA and $\beta$-TCP can provide an effective matrix of osteogenic differentiation once the material is FDM 3D printed. Table 1 and Figures 1, 2 show PLA/ $\beta$-TCP filament weight ratio percentages achieved when the two materials were combined. The flexural strength of PLA was higher than the tensile strength, as usually occurring in brittle materials with a low elongation percentage. The addition of $\beta$-TCP decreased the high strength of PLA and improved its low flexibility, resulting in a material that was improved in its tensile and elongation properties. Hardness did not show any significant modification in any of the PLA $/ \beta$-TCP ratios tested. When comparing the results of all PLA/ $\beta$-TCP ratios, PLA-10 demonstrated less modification when compared to PLA alone, followed by PLA5 and lastly by PLA- 20 .

An early study compared $\beta$-TCP in 10 and $20 \mathrm{wt} \%$ incorporated within a PLA matrix by only using Live/Dead fluorescence staining and SEM to evaluate the viability and distribution of human adipose stem cells on the scaffolds and found no differences between the two concentrations on proliferation and osteogenic differentiation of ASCs (Haimi et al., 2009). Our study found a slight difference between 20 and $10 \%$, with the second one being better. Moreover, we used qPCR results to support our MTT and ALP findings. We performed cytotoxicity assessments on different PLA to $\beta$-TCP ratios, extracted over different periods of time, and found that PLA-10 (PLA 90\%/ $\beta$-TCP 10\%) enhanced MG-63 cell proliferation and osteogenic differentiation. The ALP test indicated that PLA-10 induced the most cells into osteoblast differentiation (Figure 7). Real-time qPCR results matched those 

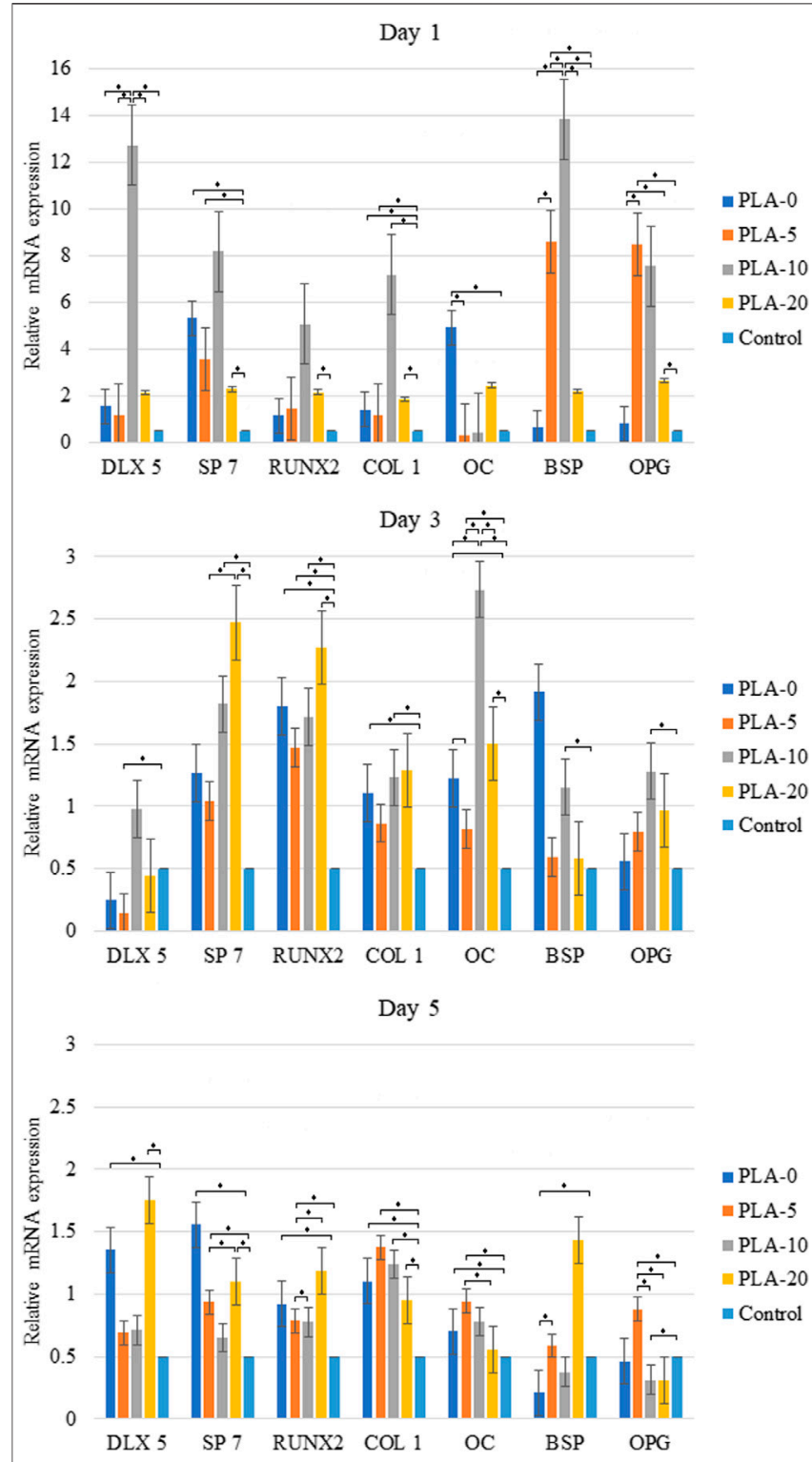

FIGURE 8 | Real-time polymerase chain reaction indicated higher osteoblast lineage gene expression from cells cultured on the PLA-10 filament medium at 5 days when compared to those cultured in DMEM $\left({ }^{*} p<0.05\right)$.

of ALP, with DLX5, SP7, OPG, OC, BSP, and RUNX2 gene expressions in cells cultured on PLA-10 and PLA-20 filaments but no RANKL gene expression, essential for osteoclast differentiation. The DLX5 gene is expressed in osteoblastogenesis (Morini et al., 2010), and RUNX2 plays an essential role in osteoblast differentiation (Park et al., 2010) in that its expression is upregulated in immature osteoblasts but downregulated in mature osteoblasts (Komori, 2009). Both RUNX2 and SP7 are essential transcription factors for osteoblast differentiation at an early stage (Yoshida et al., 2012). The early-stage osteogenic differentiation marker gene COL-1 (Hatakeyama et al., 2013) was higher for cells cultured on PLA-10 at days 1, 3, and 5. These findings altogether with the general lower expression of OPG and OC showed that cells cultured on PLA-10 had greater early-stage gene expressions in osteoblast-like cells, followed by cells cultured on PLA-20, but none of the cells on any of the PLA/ $\beta$-TCP filaments showed matured osteoblast-like cell gene expressions, with only earlystage gene expressions during all the time sets.

A systematic review on the role of PLA in bone regeneration showed that PLA modified with an osteoinductive material, such as $\beta$-TCP or HAp crystals, showed better acceptance than PLA alone (Rajendran and Venugopalan, 2015). Furthermore, previous studies have used only a PLA/ $\beta$-TCP composite to make membranes in GBR treatment, but this mixture is still not fully understood in a 3D-printed form (Haimi et al., 2009). Shim et al. (Shim et al., 2017) used a similar polymer to PLA, in an alveolar bone defect in a beagle model to show that $3 \mathrm{D}$ printed membranes in a ratio of $80 \%$ polycaprolactone (PCL) to $20 \% \beta$-TCP were more effective than $3 \mathrm{D}$-printed PCL alone and substantially better than conventional collagen membranes in terms of biocompatibility and bone regeneration and, thus, at facilitating the reconstruction of bone defects. In our study, PLA-20 had the same ratios as those in the beagle study but had less viability and osteoblast differentiation. This suggested that PLA-10 could potentially have better results in vivo. Although Shim et al. used TCP rather than $\beta$-TCP, the results of their comparison of PLA5/TCP and PLA10/TCP demonstrated that PLA10 presented improved relative cell viability. These results are consistent with our study's cell viability findings.

Most recently, a study developed and characterized printable PLA/ $\beta$-TCP bioactive composites used to produce screw models for bone-ligament fixation (Backes et al., 2020), concluding that the 3D-printed screws exhibited excellent printability and accuracy. Therefore, the developed PLA/TCP biocomposites can be used in further biomedical applications using additive manufacturing, namely, guided tissue regeneration (GTR) engineering. In addition, Khojasteh et al. (2016) used a poly(lactic-co-glycolic) acid (PLGA)-coated $\beta$-TCP scaffold (85:15) while demonstrating similar desired results for bone tissue engineering to the ones in the present study (Khojasteh et al., 2016). Other researchers have concluded that, from their review, the design of the "ideal" bone substitute greatly depends on factors such as the intrinsic properties of the materials and the processing methodology, which greatly influence its applications (Ramesh et al., 2018). Recent studies incorporate PLA and $\beta$-TCP as additives of $3 \mathrm{D}$-printed scaffolds in different variants. PLA/ $\beta$-TCP with different hydrogels can assist the tissue to repair and regenerate (Aydogdu et al., 2019) and, as a nanofiber, can reinforce gelatin-hydrogel networks (Joshi et al., 2020). PLA/ $\beta$-TCP can have the necessary properties to be further evaluated as a good biomaterial for the treatment of bone defects (Donate et al., 2020). Furthermore, the PLA/ $\beta$-TCP 90/10 ratio could be used for FDM 3D-printed customized scaffolds in regeneration of contained bone defects based on the patient's own medical images, such as tomography scan and MRI (Chen et al., 2016), similar to the first reported human case treatment of a large periodontal osseous defect. In that case, a 3D-printed bioresorbable patient-specific polycaprolactone polymer 
scaffold and rhPDGF-BB signaling growth factor were used (Rasperini et al., 2015). 3D-printed PLA/ $\beta$-TCP 90/10 can easily be customized to the desired size, configuration, and architecture of a given defect (Park et al., 2014), increasing the time spent for pre-operative surgical planning and simultaneously decreasing the time spent during surgery.

\section{CONCLUSION}

We created and evaluated $\beta$-TCP and PLA mixture filaments for the FDM 3D printing material for bone defect regeneration. Different PLA/ $\beta$-TCP ratios were evaluated to find the most appropriate ratio for $3 \mathrm{D}$ printing while using different tests to assess the efficacy of each ratio. We performed cytotoxicity assessments of the PLA/ $\beta$-TCP mixture at different concentrations of these biomaterials extracted for different periods and found that PLA-10 enhanced MG-63 cell proliferation and osteoblast differentiation. Despite the limitation of this study, our results demonstrated that PLA/ $\beta$-TCP at a ratio of $90 \% / 10 \%$ was a better filament for FDM $3 \mathrm{D}$ printing than PLA alone, supporting its potential application in intrabony defect regeneration procedures.

\section{REFERENCES}

Abe, G. L., Sasaki, J.-I., Katata, C., Kohno, T., Tsuboi, R., Kitagawa, H., et al. (2020). Fabrication of Novel Poly (Lactic Acid/caprolactone) Bilayer Membrane for GBR Application. Dent. Mater. 36, 626-634. doi:10.1016/j.dental.2020.03.013

Ahmad, N., Gopinath, P., and Dutta, R. (2019). 3D Printing Technology in Nanomedicine. Amsterdam, Netherlands: Elsevier.

Awale, R., Ali, F., Azmi, A., Puad, N., Anuar, H., and Hassan, A. (2018). Enhanced Flexibility of Biodegradable Polylactic Acid/starch Blends Using Epoxidized palm Oil as Plasticizer. Polymers 10, 977. doi:10.3390/polym10090977

Aydogdu, M. O., Oner, E. T., Ekren, N., Erdemir, G., Kuruca, S. E., Yuca, E., et al. (2019). Comparative Characterization of the Hydrogel Added PLA/ $\beta$-TCP Scaffolds Produced by 3D Bioprinting. Bioprinting 13, e00046. doi:10.1016/j. bprint.2019.e00046

Ayrilmis, N., Kariz, M., Kwon, J. H., and Kitek Kuzman, M. (2019). Effect of Printing Layer Thickness on Water Absorption and Mechanical Properties of 3D-Printed wood/PLA Composite Materials. Int. J. Adv. Manuf Technol. 102, 2195-2200. doi:10.1007/s00170-019-03299-9

Backes, E. H., Nóbile Pires, L., Selistre-de-Araujo, H. S., Costa, L. C., Passador, F. R., and Pessan, L. A. (2020). Development and Characterization of Printable PLA/ $\beta$-TCP Bioactive Composites for Bone Tissue Applications. J. Appl. Polym. Sci. 138, 49759. doi:10.1002/app.49759

Bimboim, H., and Doly, J. (1979). A Rapid Alkaline Extraction Procedure for Screening Recombinant Plasmid DNA. Nucleic Acids Res. 7, 1513-1523.

Causa, F., Netti, P. A., Ambrosio, L., Ciapetti, G., Baldini, N., Pagani, S., et al. (2006). Poly- $\varepsilon$-caprolactone/hydroxyapatite Composites for Bone Regeneration: In Vitro Characterization and Human Osteoblast Response. J. Biomed. Mater. Res. A 76, 151-162. doi:10.1002/jbm.a.30528

Chen, X., Xu, L., Wang, Y., Hao, Y., and Wang, L. (2016). Image-guided Installation of 3D-Printed Patient-specific Implant and its Application in Pelvic Tumor Resection and Reconstruction Surgery. Comput. Methods Programs Biomed. 125, 66-78. doi:10.1016/j.cmpb.2015.10.020

Choy, C., Salamanca, E., Lin, P., Huang, H.-M., Teng, N.-C., Pan, Y.-H., et al. (2019). Argon Plasma Surface Modified Porcine Bone Substitute Improved Osteoblast-like Cell Behavior. Coatings 9, 134. doi:10.3390/coatings9020134

Chuenjitkuntaworn, B., Inrung, W., Damrongsri, D., Mekaapiruk, K., Supaphol, P., and Pavasant, P. (2010). Polycaprolactone/hydroxyapatite Composite Scaffolds:

\section{DATA AVAILABILITY STATEMENT}

The raw data supporting the conclusions of this article will be made available by the authors, without undue reservation.

\section{AUTHOR CONTRIBUTIONS}

ES, S-ML, and W-JC conceptualized the idea and prepared the original draft. T-CT and $\mathrm{H}-\mathrm{WH}$ performed the methodology. $\mathrm{C}-\mathrm{SC}$ ran the software. N-CT, Y-HP, and $\mathrm{M}-\mathrm{CH}$ supervised the work. Y-FW and C-SC were involved in formal analysis. Y-HP and $\mathrm{C}-\mathrm{KL}$ performed the investigation. W-JC obtained the resources and acquired the funding. T-CT and ES curated the data. W-JC, Y-FW, and S-ML reviewed and edited the paper. $\mathrm{N}-\mathrm{CT}$ visualized the results. $\mathrm{H}-\mathrm{WH}$ administered the project.

\section{FUNDING}

This work was supported by the grant from the Ministry of Science and Technology (grant numbers 108-2314-B-038-034 and 107-2811-B-038-519).

Preparation, Characterization, and In Vitro and In Vivo Biological Responses of Human Primary Bone Cells. J. Biomed. Mater. Res. A. 94. 241-251. doi:10.1002/ jbm.a.32657

Cipitria, A., Skelton, A., Dargaville, T. R., Dalton, P. D., and Hutmacher, D. W. (2011). Design, Fabrication and Characterization of PCL Electrospun ScaffoldsA Review. J. Mater. Chem. 21, 9419-9453. doi:10.1039/c0jm04502k

Dan, H., Vaquette, C., Fisher, A. G., Hamlet, S. M., Xiao, Y., Hutmacher, D. W., et al. (2014). The Influence of Cellular Source on Periodontal Regeneration Using Calcium Phosphate Coated Polycaprolactone Scaffold Supported Cell Sheets. Biomaterials 35, 113-122. doi:10.1016/j.biomaterials.2013.09.074

Donate, R., Monzón, M., Ortega, Z., Wang, L., Ribeiro, V., Pestana, D., et al. (2020). Comparison between Calcium Carbonate and $\beta$-tricalcium Phosphate as Additives of 3D Printed Scaffolds with Polylactic Acid Matrix. J. Tissue Eng. Regen. Med. 14, 272-283. doi:10.1002/term.2990

Haimi, S., Suuriniemi, N., Haaparanta, A.-M., Ellä, V., Lindroos, B., Huhtala, H., et al. (2009). Growth and Osteogenic Differentiation of Adipose Stem Cells on PLA/Bioactive Glass and PLA/ $\beta$-TCP Scaffolds. Tissue Eng. A 15, 1473-1480. doi:10.1089/ten.tea.2008.0241

Hallermann, W., Olsen, S. r., Bardyn, T., Taghizadeh, F., Banic, A., and Iizuka, T. (2006). A New Method for Computer-Aided Operation Planning for Extensive Mandibular Reconstruction. Plast. Reconstr. Surg. 117, 2431-2437. doi:10.1097/ 01.prs.0000219076.83890.e8

Hamzah, H. H., Shafiee, S. A., Abdalla, A., and Patel, B. A. (2018). 3D Printable Conductive Materials for the Fabrication of Electrochemical Sensors: A Mini Review. Electrochem. Commun. 96, 27-31. doi:10.1016/j. elecom.2018.09.006

Hatakeyama, W., Taira, M., Chosa, N., Kihara, H., Ishisaki, A., and Kondo, H. (2013). Effects of Apatite Particle Size in Two Apatite/collagen Composites on the Osteogenic Differentiation Profile of Osteoblastic Cells. Int. J. Mol. Med. 32, 1255-1261. doi:10.3892/ijmm.2013.1516

Jeong, J., Kim, J. H., Shim, J. H., Hwang, N. S., and Heo, C. Y. (2019). Bioactive Calcium Phosphate Materials and Applications in Bone Regeneration. Biomater. Res. 23, 1-11. doi:10.1186/s40824-018-0149-3

Joshi, M. K., Lee, S., Tiwari, A. P., Maharjan, B., Poudel, S. B., Park, C. H., et al. (2020). Integrated Design and Fabrication Strategies for Biomechanically and Biologically Functional PLA/ $\beta$-TCP Nanofiber Reinforced GelMA Scaffold for Tissue Engineering Applications. Int. J. Biol. Macromolecules 164, 976-985. doi:10.1016/j.ijbiomac.2020.07.179 
Khojasteh, A., Fahimipour, F., Eslaminejad, M. B., Jafarian, M., Jahangir, S., Bastami, F., et al. (2016). Development of PLGA-Coated $\beta$-TCP Scaffolds Containing VEGF for Bone Tissue Engineering. Mater. Sci. Eng. C 69, 780-788. doi:10.1016/j.msec.2016.07.011

Komori, T. (2009). "Regulation of Osteoblast Differentiation by Runx2," in Osteoimmunology. Boston, MA: Springer, 43-49. doi:10.1007/978-1-4419-1050-9_5

LeGeros, R. Z., Lin, S., Rohanizadeh, R., Mijares, D., and Legeros, J. P. (2003). Biphasic Calcium Phosphate Bioceramics: Preparation, Properties and Applications. J. Mater. Sci. Mater. Med. 14, 201-209. doi:10.1023/a: 1022872421333

LeGeros, R. Z. (1988). Calcium Phosphate Materials in Restorative Dentistry: a Review. Adv. Dent Res. 2, 164-180. doi:10.1177/08959374880020011101

Livak, K. J., and Schmittgen, T. D. (2001). Analysis of Relative Gene Expression Data Using Real-Time Quantitative PCR and the $2-\Delta \Delta C T$ Method. methods 25, 402-408. doi:10.1006/meth.2001.1262

Moreno, D., Vargas, F., Ruiz, J., and López, M. E. (2020). Solid-state Synthesis of Alpha Tricalcium Phosphate for Cements Used in Biomedical Applications. Bol. Soc. Esp. Cerám. 59, 193-200. doi:10.1016/j.bsecv.2019.11.004

Morini, M., Astigiano, S., Gitton, Y., Emionite, L., Mirisola, V., Levi, G., et al. (2010). Mutually Exclusive Expression of DLX2 and DLX5/6 Is Associated with the Metastatic Potential of the Human Breast Cancer Cell Line MDA-MB-231. $B M C$ cancer 10, 649. doi:10.1186/1471-2407-10-649

Murphy, S. V., and Atala, A. (2014). 3D Bioprinting of Tissues and Organs. Nat. Biotechnol. 32, 773-785. doi:10.1038/nbt.2958

Ohgushi, H., Okumura, M., Tamai, S., Shors, E. C., and Caplan, A. I. (1990). Marrow Cell Induced Osteogenesis in Porous Hydroxyapatite and Tricalcium Phosphate: a Comparative Histomorphometric Study of Ectopic Bone Formation. J. Biomed. Mater. Res. 24, 1563-1570. doi:10.1002/jbm.820241202

Park, E.-S., Lind, A.-K., Dahm-Kähler, P., Brännström, M., Carletti, M. Z., Christenson, L. K., et al. (2010). RUNX2 Transcription Factor Regulates Gene Expression in Luteinizing Granulosa Cells of Rat Ovaries. Mol. Endocrinol. 24, 846-858. doi:10.1210/me.2009-0392

Park, C. H., Rios, H. F., Taut, A. D., Padial-Molina, M., Flanagan, C. L., Pilipchuk, S. P., et al. (2014). Image-based, Fiber Guiding Scaffolds: a Platform for Regenerating Tissue Interfaces. Tissue Eng. C: Methods 20, 533-542. doi:10. 1089/ten.tec.2013.0619

Rajendran, T., and Venugopalan, S. (2015). Role of Polylactic Acid in Bone Regeneration-A Systematic Review. J. Pharm. Sci. Res. 7, 960.
Ramesh, N., Moratti, S. C., and Dias, G. J. (2018). Hydroxyapatite-polymer Biocomposites for Bone Regeneration: A Review of Current Trends. J. Biomed. Mater. Res. 106, 2046-2057. doi:10.1002/jbm.b.33950

Rasperini, G., Pilipchuk, S. P., Flanagan, C. L., Park, C. H., Pagni, G., Hollister, S. J., et al. (2015). 3D-printed Bioresorbable Scaffold for Periodontal Repair. J. Dent Res. 94, 153S-157S. doi:10.1177/0022034515588303

Salamanca, E., Hsu, C. C., Yao, W. L., Choy, C. S., Pan, Y. H., Teng, N.-C., et al. (2020). Porcine Collagen-Bone Composite Induced Osteoblast Differentiation and Bone Regeneration In Vitro and In Vivo. Polymers 12, 93. doi:10.3390/ polym 12010093

Shim, J.-H., Won, J.-Y., Park, J.-H., Bae, J.-H., Ahn, G., Kim, C.-H., et al. (2017). Effects of 3D-Printed Polycaprolactone/ $\beta$-Tricalcium Phosphate Membranes on Guided Bone Regeneration. Ijms 18, 899. doi:10.3390/ijms18050899

Sollazzo, V., Palmieri, A., Scapoli, L., Martinelli, M., Girardi, A., Alviano, F., et al. (2010). Bio-Oss ${ }^{\circledR}$ Acts on Stem Cells Derived from Peripheral Blood. Oman Med. J. 25, 26. doi:10.5001/omj.2010.7

Takagi, T., Aoki, A., Ichinose, S., Taniguchi, Y., Tachikawa, N., Shinoki, T., et al. (2018). Effective Removal of Calcified Deposits on Microstructured Titanium Fixture Surfaces of Dental Implants with Erbium Lasers. J. Periodontol. 89, 680-690. doi:10.1002/jbm.b.33950

Vogelstein, B., and Gillespie, D. (1979). Preparative and Analytical Purification of DNA from Agarose. Proc. Natl. Acad. Sci. 76, 615-619. doi:10.1073/pnas.76. 2.615

Yoshida, C. A., Komori, H., Maruyama, Z., Miyazaki, T., Kawasaki, K., Furuichi, T., et al. (2012). SP7 Inhibits Osteoblast Differentiation at a Late Stage in Mice. PloS one 7, e32364. doi:10.1371/journal.pone.0032364

Conflict of Interest: The authors declare that the research was conducted in the absence of any commercial or financial relationships that could be construed as a potential conflict of interest.

Copyright (c) 2021 Salamanca, Tsao, Hseuh, Wu, Choy, Lin, Pan, Teng, Huang, Lin and Chang. This is an open-access article distributed under the terms of the Creative Commons Attribution License (CC BY). The use, distribution or reproduction in other forums is permitted, provided the original author(s) and the copyright owner(s) are credited and that the original publication in this journal is cited, in accordance with accepted academic practice. No use, distribution or reproduction is permitted which does not comply with these terms. 